\title{
A Declaração de Belém(*)
}

Excelências,

Minhas Senhoras, meus Senhores:

A Declaração de Belém, roteiro de ação do Tratado de Cooperacão Amazônica, que vem de ser firmada, inspira-se em duas idéias centrais. A primeira é a vocação da Amazônia para unir os países da América Latina entre si e com as demais nações do mundo tropical

A segunda é a fé em nossa capacidade de desenvolver esta área. E de transformar em realidade o potencial das Terras do Sem-Fim de Cobra Norato. Os sete milhões de quilômetros quadrados do subcontinente amazônico. E suas águas do Sem-Fim: mais de um quinto da água doce da superfície do globo.

Não faz muito tempo, as crianças ainda aprendiam que os rios amazônicos de planície nada tinham a oferecer em matéria de energia.

Que os solos eram aqui uniformemente pobres. O ecossistema demasiado frágil. A agricultura regular impossível. E que não havia lugar, na geologia sedimentar da Amazônia, para províncias minerais importantes. Tudo isso haveria de ser desmentido e infirmado pela presença do homem, animado da vontade e do espírito de aventura e pioneirismo.

Caudais volumosos transformam-se em realizações tangiveis de geração de energia, como em Tucuruí.

Outros, como o Tocantins-Araguaia, o Xingu, o Tapajós, os cursos dos contrafortes andinos, aguardam seu encontro com o engenho dos homens e com a história.

A experiência da colonização espontânea de Rondônia fez brotar cidades do que era nada. Por lá vicejam, agora, -- ao lado do cacau, da seringueira, do guaraná, da pimenta e do café - culturas de cereais, de soja e de cana-de-açúcar.

$\mathrm{Na}$ região, afinal, encontraram-se minerais sem conta.

Aqui, a cassiterita; ali a bauxita; mais além, o ferro, o manganês, o níquel, o cobre, o ouro. Por todos os lados a terra abre o seio generoso que abrigou riquezas não sonhadas pelos que penetraram a floresta e desvendaram seus mistérios.

A própria crise energética abre à Amazônia perspectivas de novas riquezas. Destas terras surge o petróleo que revoluciona a economia dos países que o possuem.

E, à medida que se esgota a energia fóssil. a Amazônia oferece fontes literalmente inesgotáveis de biomassa. Ou seja, de conversão da energia solar em combustiveis, através da fotossintese.

(*) - Discurso pronunciado por Sua Excelência o Senhor Presidente da República Federativa do Brasil, na Sessão de Encerramento da 1.a Reunião dos Ministros das Relaçōes Exteriores do Tratado de Cooperação Amazônica, Belém, 24 de outubro de 1980 . 
Alcool, metanol, óleos vegetais e outros sucedâneos do petróleo podem ser aqui obtidos, hoje, a custos compensadores.

A verdade é que o agricultor simples e corajoso, o trabalhador que povoa a Amazônia, demonstra com a linguagem dos fatos e a eloqüência do trabalho realizador aquilo que tive oportunidade de dizer em Manaus, em outubro de 1978:

"Nāo considero necessário sacrificar nossa reserva florestal para fazer agricultura e pecuária. Nem admito que o progresso seja feito à custa do esmagamento do nosso ecossistema, do equilíbrio natural que Deus decretou para este pedaço majestoso do mundo".

"Nosso desenvolvimento deverá ser realizado com o mínimo irredutivel de ofensa à natureza".

Nesse sentido, o Governo brasileiro está ultimando a legislação que definirá uma política florestal para a Amazônia brasileira. O objetivo dessa política é harmonizar a utilização das potenciaiidades econômicas da Região com a preservação dos seus recursos naturais .

\section{Senhores Chanceleres, Excelências:}

Nesta cidade de Belém do Pará, juntam-se o mundo amazônico e o mundo atlântico. Há quase 350 anos, o Capitão-Mor Pedro Teixeira daqui partiu para refazer - em sentido inverso, até os Andes - o percurso da trágica expedição de Francisco Orellana.

Depois, foram as expedições missionárias, junto com os que buscavam o sertão e os altos rios. Lá ponteava a árvore da borracha. E ao lado da fera à espreita, a doença e a morte.

Mas foi assim que surgiram e cresceram Belém, Manaus e iquitos, centros do ciclo da borracha, mas centros de civilização continente adentro.

Este mesmo Teatro da Paz, de nome tão sugestivo, moldura majestosa de nossa conferência, data do século XIX. Os templos, os fortes e os palácios de Belém, são testemunhas da beleza de um passado glorioso e próspero - mas efêmero.

Vivida e aprendida essa lição, não nos basta, hoje, reeditar surtos econômicos dependentes do extrativismo e das oscilaçōes dos mercados externos.

O que buscamos é promover o desenvolvimento da Região. Harmonioso. Pleno. Auto-sustentável. Integrado ao processo global de expansão das economias nacionais de cada um dos países. Esse o nosso esforço. Isso procuramos tornar realidade no Brasil

Adotamos uma política de incentivos fiscais destinada a acelerar o desenvolvimento da Amazônia.

Promovemos a abertura de estradas. Cada uma delas estende-se por milhares de quilômetros e oferece à agropecuária milhões de hectares de terras novas. 
Ativamos o programa de pólos de desenvolvimento. A ação das agências de desenvolvimento regional, como a SUDAM, a SUFRAMA, o Banco da Amazônia, resultou em 500 projetos em execuçãc, na indústria, na agricultura e na pecuária.

Confiança na Amazônia é, portanto, antes de tudo, confiança em nós mesmos.

Assumimos a nossa condição de habitantes do mundo tropical. Quer dizer: vamos transformá-lo em ambiente propício à plena realização do homem.

No norte da América do Sul, entre a Bolívia, a Colômbia, o Equador, a Guiana, o Peru, o Suriname, a Venezuela e o Brasil, o denominador comum é a Amazônia.

Não podemos deixar desaproveitado esse imenso elemento de aproximação diplomática e catalisador de interesse e problemas comuns.

Para esse fim, temos de criar a ciência e desenvolver a tecnologia adequada às condições climáticas, do solo e da ecologia no trópico úmido e ao longo da Linha do Equador.

Só nós, os países amazônicos, poderemos fazê-lo. Sem desprezar a cooperação de cientistas de outras latitudes, temos de reconhecer que a experiência é aqui. As nações desenvolvidas não têm lições a dar-nos em matéria tropical.

Temos de inventar e aperfeiçoar, como já estamos fazendo, técnicas e métodos de baixo custo, nascidos da própria realidade regional. Sem sofisticações inúteis. Utilizando matérias-primas locais. Mas, sobretudo, com uso intensivo do nosso recurso mais abundante: o trabalho criador de nossa gente.

Assim, estaremos assegurando a elevação do nivel e da qualidade da vida de nossos povos e construindo sociedades prósperas e avançadas.

Assim, só assim, criaremos condições para suprimir a miséria e a doença. Para gerar conhecimentos e recursos capazes de proteger o meio-ambiente, não pela renúncia a ação, mas por meio da atividade planejada e racional. Belém:

Como tive ocasião de dizer em agosto de 1978, aqui mesmo, em

"Rica e selvagem, quão bela e frágil, a Amazônia não é só uma enorme extensão de terra a cultivar e dividir. Essa é uma visão materialista da região..." "que obviamente nossos países também não podem aceitar.

Entre a centena e meia de nações que conformam o universo do subdesenvolvimento, uma nítida maioria situa-se na faixa tropical. Esses países poderão beneficiar-se da criação de energia a partir da biomassa; da produção intensiva de alimentos; dos sistemas de saúde pública e medicina tropical testados na Amazônia. Deles teremos, também, muito a receber. 
Esse tipo de colaboração é essencial para que os grandes problemas do nosso tempo encontrem soluçōes adequadas.

Reconhecemos como indispensável, porém, que os paises favorecidos pela concentração do poder político e econômico se disponham a desempenhar a parte que lhes toca.

Deles depende, e não de nós, reduzirem-se as tensões conseqüentes a estéreis competiçōes hegemônicas. Inverter a direção da corrida armamentista. Aceitar regras de comércio que tornem possivel o desenvolvimento da grande maioria da humanidade.

Não obstante a persistente surdez dos países industrializados, continuaremos serenamente a erguer nossa voz para formular propostas construtivas de diálogo.

Ao mesmo tempo, na esfera a nosso alcance, trabalharemos para que se transforme em realidade o ideal de intensificar a cooperação entre paises em desenvolvimento.

Nesse dominio, o Brasil tem feito o que the compete, com palavras e, sobretudo, com ações.

Refutamos na prática a teoria da impossibilidade de complementação econômica entre os subdesenvolvidos. Hoje, cerca de $29 \%$ do total do comércio internacional brasileiro é feito com parceiros em desenvolvimento.

Senhores Chanceleres, Excelências,

Por feliz coincidência, a Primeira Reunião dos Chanceleres Amazônicos se encerra no próprio Dia das Naçōes Unidas. É como se desejássemos simbolizar a união de esforços nacionais, parte inseparável do processo de cooperação regional aqui instaurado.

A Declaração de Belém, hoje assinada, permite-nos também comemorar, de forma solene, o $35 .^{\circ}$ aniversário da entrada em vigor da Carta de São Francisco. Por seus propósitos e princípios, ela é o documento básico da comunidade mundial, neste Século XX.

O Tratado de Cooperação Amazônica, que ora inicia sua fase operacional, inscreve-se nesse mesmo esforço transformador da convivência internacional.

Por todos esses motivos, reitero a Vossas Excelências, Senhores Chanceleres, os agradecimentos do Governo brasileiro e do povo desta região pela honrosa presença e brilhante participação com que nos distinguiram na reunião.

Solicito a Vossas Excelências que se façam intérpretes dos meus anseios pela crescente prosperidade da Bolívia, da Colômbia, do Equador, da Guiana, do Peru, do Suriname e da Venezuela. Peço-Ihes transmitirem os votos que formulo pela felicidade pessoal de seus Chefes de Estado.

Ao finalizar, quero renovar minha confiança de que, unidos e solidários, avançaremos melhor e mais rapidamente em benefício de todos os povos irmanados na própria idéia da Amazônia.

Muito obrigado. 